XI1.-Action of Benzyl Chloride on Laurel Camphor (Laurus Camphora). Part I. Preliminary Notice.

\title{
By Donato Tommas.
}

WHEN 160 grams of camphor and 300 grams of henzyl chloride, together with 30 grams of powdered zinc, are introduced into a retort, no reaction takes place at the ordinary temperature, but if the retort be gently warmed, a violent reaction immediately takes place, with disengagement of abundance of hydrochloric acid. The reaction is allowed to continue until it ceases, and the product is then distilled in a sand-bath, when a very acid liquid, which is coloured slightly brown, passes over. To purify this liquid, it is heated with dry potassium carbonate, and when completely neutralised, it is digested for 24 hours with calcium chloride. The liquid thus deprived of its hydrochloric acid and water is again distilled without a thermometer. Two products are thus separated, a liquid which passes over, and a very viscous liquid which remains in the retort. This viscous liquid deposits a crystalline substance which may be separated from it by filtration and pressure. The crystalline substance is purified by solution in boiling alcohol, to which a small portion of animal charcoal has been added, and the alcoholic solution deposits on cooling a slightly yellow crystalline substance having the smell of camphor.

This substance, which I have not yet analysed, may be camphor not attacked by the benzyl chloride, or perhaps it may consist of chlorides of camphene.

The liquid portion, after four practical distillations, is resolved into several compounds having the following boiling-points :-

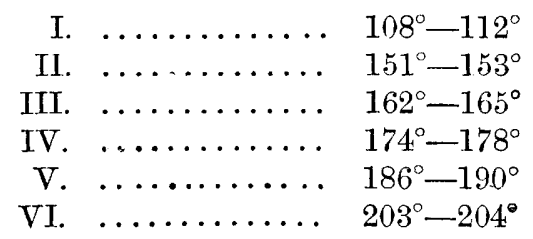

Besides these compounds there are others which, in consequence of their small quantity, I have been unable to separate by distillation. These are liquids having the following boiling-points :-

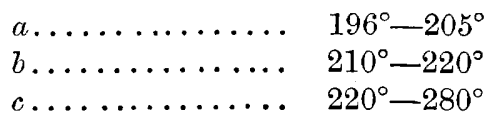

All these products are liquid at the ordinary temperature, insoluble 
in water, and lighter than that liquid. They all possess an agreeable odour, recalling the odour of oil of turpentine and of benzene. They burn with a bright but smoky flame.

\section{Analysis of Product No. 1.}

The liquid boiling between $108^{\circ}-112^{\circ}$ was redistilled, and the product which came over between $110^{\circ}-112^{\circ}$ gave, on analysis, the following numbers :-

$$
\begin{array}{lrr}
\text { Carbon } \ldots \ldots \ldots \ldots \ldots . & 90 \cdot 87 \\
\text { Hydrogen } \ldots \ldots \ldots \ldots . & 8 \cdot 78
\end{array}
$$

The formula deduced from these numbers is very close to that of toluene ; in fact, the formula of that hydrocarbon requires-

$$
\begin{array}{lrr}
\text { Carbon } \ldots \ldots \ldots \ldots \ldots & 91.30 \\
\text { Hydrogen } \ldots \ldots \ldots \ldots & 8.69
\end{array}
$$

Moreover, on comparing the boiling-points of the two substances, it is impossible not to recognise their identity. I would call attention to the fact that this is one of the most abundant of the products of the action of benzyl chloride on camphor, and as the benzyl chloride employed by me contains no traces of toluene, this hydrocarbon cannot have been produced, except by the action of nascent hydrogen (produced by the decomposition of the hydrochluric acid by the zinc) on the benzyl chloride.

Thus: $\mathrm{C}_{7} \mathrm{H}_{7} \mathrm{Cl}+\mathrm{H}_{2}=\mathrm{C}_{7} \mathrm{H}_{8}+\mathrm{HCl}$.

In future communications which I shall have the honour of submitting to the consideration of the Chemical Society, I intend to study in detail the constitutional formulæ as well as the physical and chemical properties of the different products of which I now merely indicate the existence. 